\title{
A Compact Wideband Dual-Polarized Antenna with Harmonic Suppression Using Nonuniform Defected Ground Structure
}

\author{
Lana Damaj, Anne-Claire Lepage, and Xavier Begaud \\ Comelec Department, Institut Mines-Télécom, Télécom ParisTech, LTCI CNRS UMR 5141, 46 rue Barrault, \\ 75634 Paris Cedex 13, France \\ Correspondence should be addressed to Xavier Begaud; xavier.begaud@telecom-paristech.fr
}

Received 13 June 2014; Revised 23 August 2014; Accepted 10 September 2014

Academic Editor: Renato Cicchetti

Copyright (C) 2015 Lana Damaj et al. This is an open access article distributed under the Creative Commons Attribution License, which permits unrestricted use, distribution, and reproduction in any medium, provided the original work is properly cited.

A wideband dual-polarized coplanar waveguide (CPW) fed antenna integrating a wide stop-band filter is presented. The designed filter is based on a nonuniform defected ground structure (DGS) in order to obtain a wide stop-band and a compact size. This filter is used to reject harmonics and spurious radiation arising from the RF front end. The complete structure (antenna and filter) has been optimized to have a compact size of $0.6 \times 0.6 \lambda_{0}^{2}\left(\lambda_{0}\right.$ being the free-space wavelength at the lowest operating frequency). The realized antenna operates in the frequency range between $2.7 \mathrm{GHz}$ and $5.9 \mathrm{GHz}$ (bandwidth of about 74\%). The isolation between feeding ports is more than $18 \mathrm{~dB}$. The complete structure has a wide stop-band characteristic (103\%) for harmonic rejection. The simulated numerical results have been confirmed with measurements.

\section{Introduction}

An active integrated antenna (AIA) introduces nonlinear devices directly into the radiating element. This concept was used to design antennas including high efficiency power amplifiers. However, these antennas exhibit high levels of harmonic radiation, which may degrade system performances [1]. In conventional systems, additional filters are used to remove these harmonics. However, these filters increase the size and the cost of radio frequency (RF) front ends and yield additional losses. Thus, it is interesting to perform this filtering function directly within the radiating element. This type of antenna allows the realization of compact RF front ends.

Several methods have been used to reject harmonics such as the insertion of slots and short-circuits [2] and the use of photonic band gap (PBG) $[3,4]$ or defected ground structure (DGS) $[5,6]$. Finally, it should be noted that most studies have been carried out for narrowband structures.

A wideband antenna supporting a single field polarization has been recently presented in $[7,8]$. Using these results, in this paper the design of a wideband dual-polarized antenna, in which the matching circuit and the filter for harmonic rejection are integrated in the radiating element, is presented. The challenge was to reduce the isolation between the two input ports while maintaining a wide bandwidth and a compact size. Furthermore, a study about the radiation characteristics of the filter has been performed. The antenna provides wide bandwidth and dual polarization performance, in order to cover many communication standards and to transmit or receive any kind of field polarization (linear or circular). In [9], it has been shown that the diffraction processes arising from the presence of furniture may reduce the communication quality in indoor environments. Therefore, antennas that provide dual or circular polarization may be used to improve the service quality. On the other hand, the filter and the matching network are integrated parts of the radiating element. In this work, the radiating element, the filter for harmonic rejection, and the impedance matching network, which are traditionally separated circuits, are incorporated into a single unit.

The configuration of the proposed filter is shown in Section 2. Section 3 describes the design and the simulated and the measured results of the proposed antenna. The 


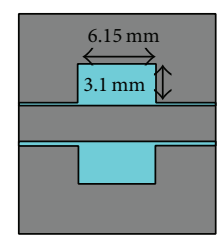

(a)

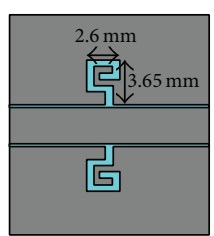

(b)

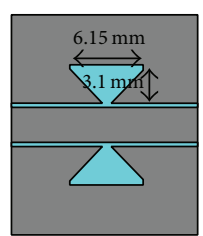

(c)

FIGURE 1: DGS unit cells: (a) rectangular, (b) spiral, and (c) bowtie.

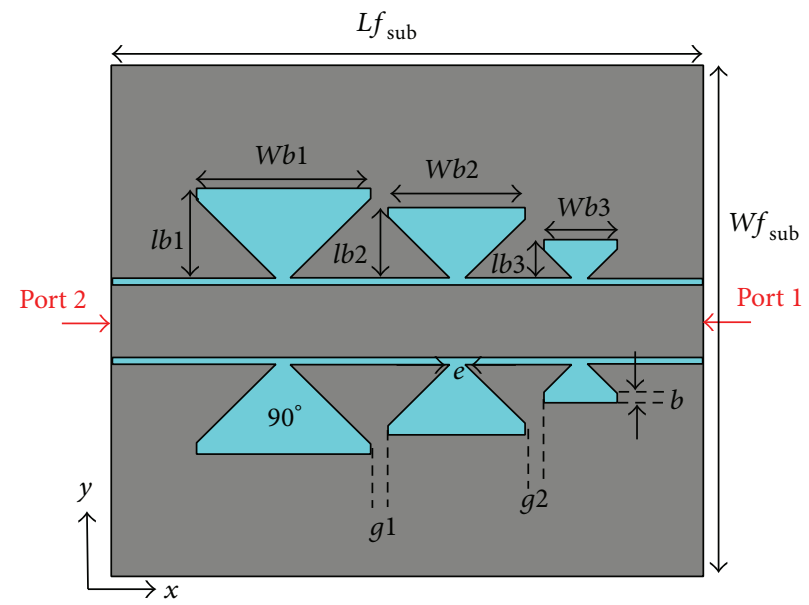

FIGURE 2: Geometry of the DGS filter.

discussion about the filter radiation is presented in Section 4. Finally, a conclusion of this work is given in Section 5.

\section{DGS Filter Design}

The filter is based on a defected ground structure (DGS) formed by three nonuniform unit cells. A DGS is a kind of electromagnetic band gap (EBG) structure. EBG structures forbid the propagation of electromagnetic waves in certain frequency bands known as band gaps. This property is used in many applications for the suppression of higher harmonics and undesirable frequency bands. DGS has the same advantages as the ones proposed by EBG structures in terms of size miniaturization, suppression of surface waves, and the ability to introduce distinctive stop-bands. The advantage of DGS over the EBG structures is that only one or few cells are needed instead of a periodic structure to produce the same performances. A DGS unit cell is a defect in the ground plane of a transmission line as that of a microstrip, coplanar, or any structure where a reference ground plane conductor exists. A variety of slot geometries have been proposed in the literature for filter design [10-12]. A parametric study has been carried out on three different compact geometries (rectangular, spiral, and bowtie) to select the most adapted unit useful to design the integrated filter (see Figure 1).

Table 1 summarizes the comparative study of the magnitude of the scattering parameter $S_{21}\left(\left|S_{21}\right|\right)$ of each DGS unit cell. Simulations were performed with CST MWS (transient solver). The rejected bandwidth refers to a $\left|S_{21}\right|$ less than
TABLE 1: Rejected bandwidth for DGS unit cells.

\begin{tabular}{lcc}
\hline Unit cells & Rejected band $(\mathrm{GHz})$ & Bandwidth $(\%)$ \\
\hline Rectangular & $20.9-24.4$ & 15.45 \\
Spiral & $7.2-8$ & 10.5 \\
Bowtie & $9.6-12.55$ & 26.6 \\
\hline
\end{tabular}

$-15 \mathrm{~dB}$. After a comparison of the characteristics of several cells, bowtie unit cell was chosen because it has the widest rejected bandwidth and a compact size.

The designed filter is formed by means of three nonuniform cascaded unit cells, in order to obtain a wide rejected band and a compact size, to be integrated with the antenna. Figure 2 shows the configuration of the adopted DGS filter.

The filter is printed on a FR4 substrate $\left(\varepsilon_{r}=3.7, \tan \delta=\right.$ 0.02 , and $h=0.8 \mathrm{~mm}$ ). The total size of the filter is $0.36 \times$ $0.33 \lambda_{0}^{2}$, where $\lambda_{0}$ is the free-space wavelength at $5.5 \mathrm{GHz}$. The dimensions of the unit cell have been optimized by a means of a parametric study of the bowtie unit cell to reject the undesired band from $7 \mathrm{GHz}$ up to $22 \mathrm{GHz}$.

The physical parameters of the filter, shown in Figure 2, are listed in Table 2. The simulated scattering parameters $\left(\left|S_{11}\right|\right.$ and $\left|S_{21}\right|$, resp.) of the proposed filter are shown in Figure 3. They were obtained with CST Microwave Studio.

The $3 \mathrm{~dB}$ cut-off frequency of the filter is $5.5 \mathrm{GHz}$ and the rejected band is between $7 \mathrm{GHz}$ and $22 \mathrm{GHz}(103 \%)$ for a $\left|S_{21}\right|$ less than $-15 \mathrm{~dB}$. 


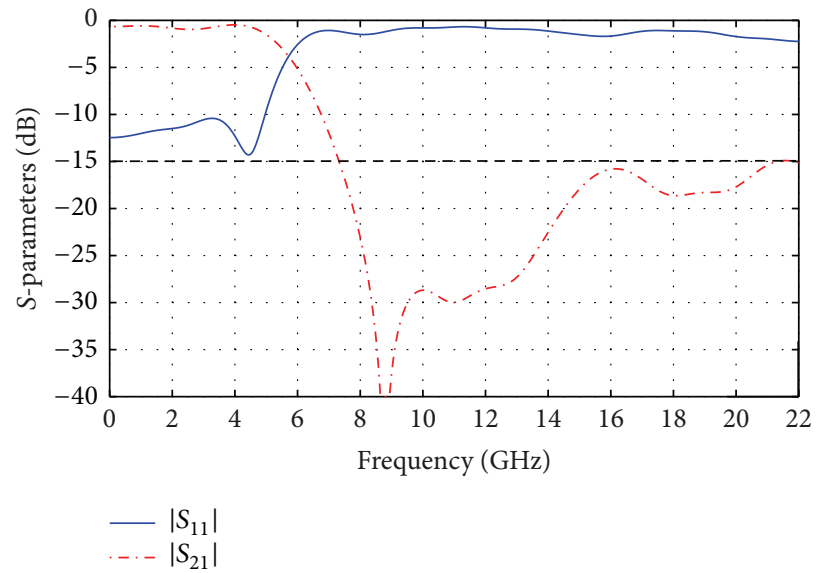

FIGURE 3: Magnitude of the filter scattering parameters versus frequency.

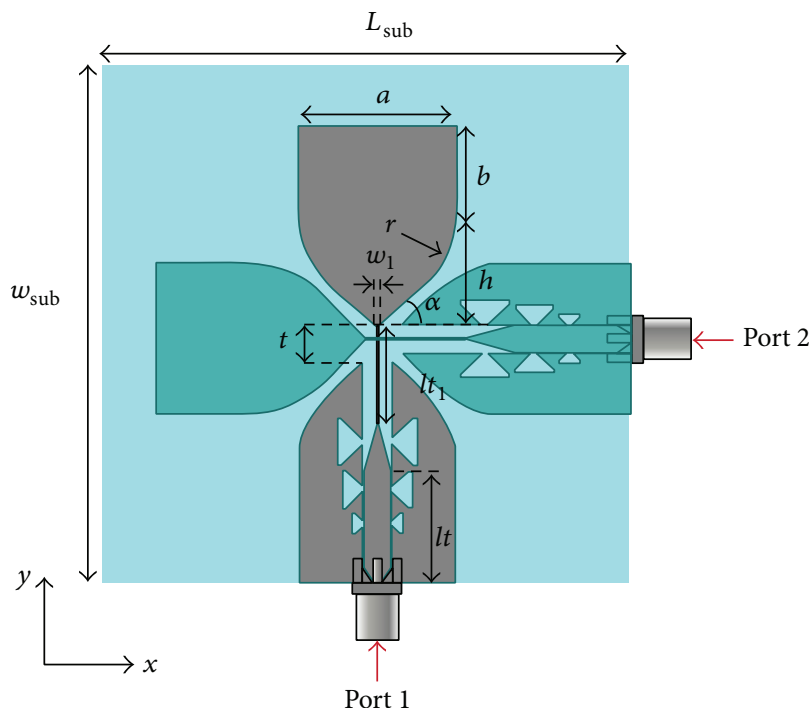

FIGURE 4: Geometry of the proposed antenna.

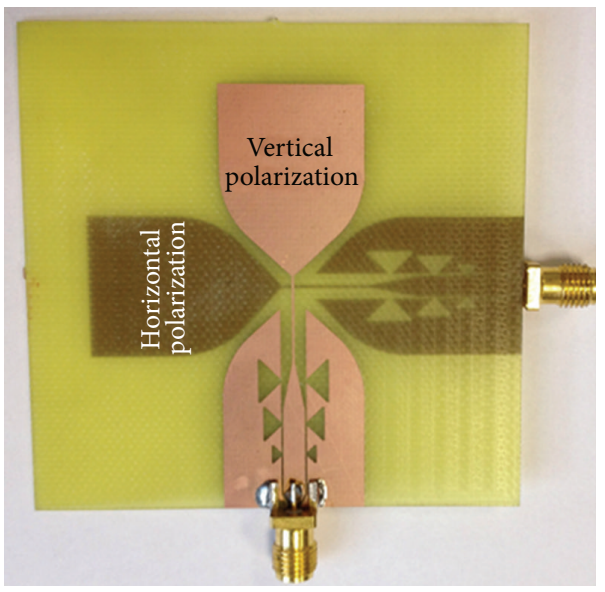

Figure 5: Prototype of the proposed antenna. 


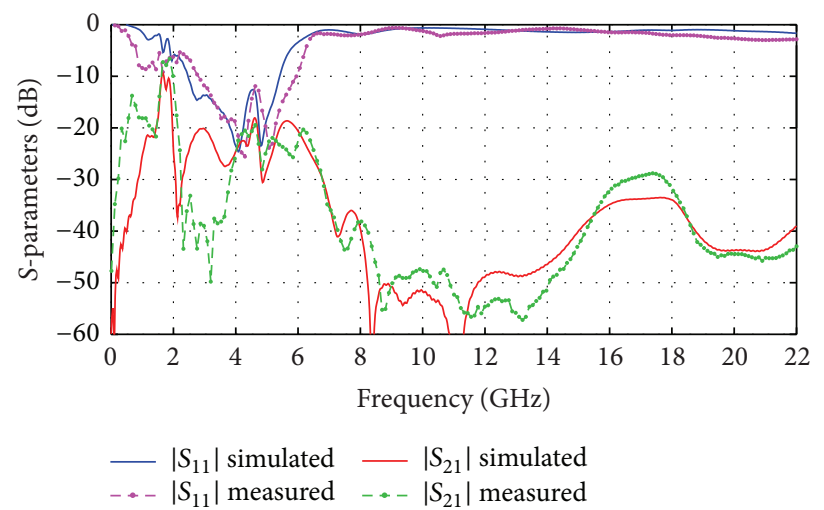

Figure 6: Magnitude of the antenna scattering parameters versus frequency.

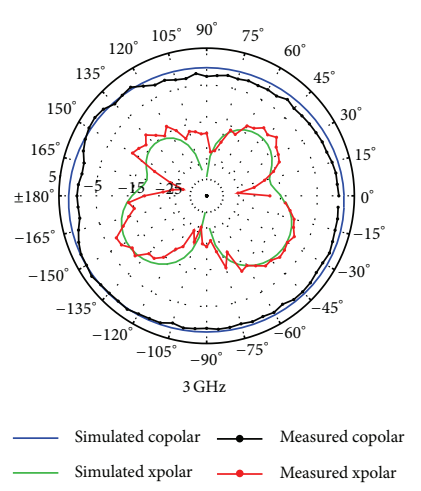

(a)

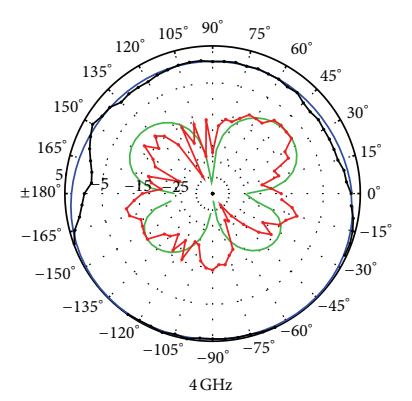

$\begin{array}{lll}- & \text { Simulated copolar } \rightarrow \text { Measured copolar } \\ - \text { Simulated xpolar } \rightarrow-\text { Measured xpolar }\end{array}$

(b)

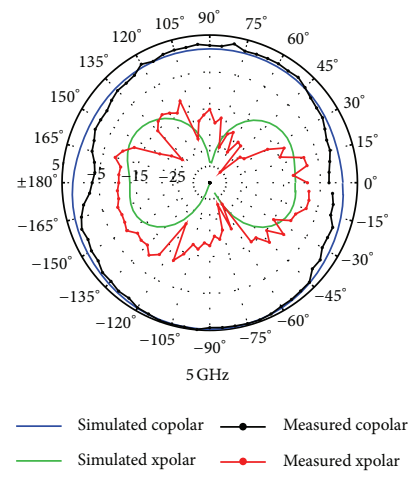

(c)

FIGURE 7: Simulated and measured radiation pattern in the H-plane (xoz) (10 dB/div).

TABLe 2: Physical parameters of the filter.

\begin{tabular}{lccc}
\hline Parameters & Values $(\mathrm{mm})$ & Parameters & Values $(\mathrm{mm})$ \\
\hline $\mathrm{Lf}_{\text {sub }}$ & 20 & $\mathrm{~Wb} 1$ & 6.15 \\
$\mathrm{Wf}_{\text {sub }}$ & 18 & $\mathrm{~Wb} 2$ & 4.9 \\
\hline$e$ & 0.5 & $\mathrm{~Wb} 3$ & 2.6 \\
$g 1$ & 0.8 & $\mathrm{lb} 1$ & 3.1 \\
$g 2$ & 0.3 & $\mathrm{lb} 2$ & 2.5 \\
$b$ & 0.3 & $\mathrm{lb3}$ & 1.36 \\
\hline
\end{tabular}

\section{The Proposed Antenna}

The complete structure is composed of a dual-polarized antenna within which the DGS filter is inserted (see Figure 4).

The antenna is formed by two bowtie radiating elements. One radiating element is printed on the top of the substrate (FR4, $\varepsilon_{r}=3.7, \tan \delta=0.02$, and $h=0.8 \mathrm{~mm}$ ) and the other one is rotated by $90^{\circ}$ and printed on its bottom side, without any connection between these two structures. Both elements are fed with a coplanar waveguide (CPW) through a wideband transition used as a matching circuit. This transition transforms the input impedance of the antenna, close to $160 \Omega$, into $50 \Omega$ at the SMA connector. The filter is
TABLE 3: Physical parameters of the complete structure.

\begin{tabular}{lccc}
\hline Parameters & Values $(\mathrm{mm})$ & Parameters & Values \\
\hline$L_{\text {sub }}$ & 67 & $r$ & $12 \mathrm{~mm}$ \\
$w_{\text {sub }}$ & 67 & $\alpha$ & $43^{\circ}$ \\
$h$ & 14 & $w_{1}$ & $0.3 \mathrm{~mm}$ \\
$b$ & 11.8 & $t$ & $4.6 \mathrm{~mm}$ \\
$a$ & 19.4 & $\mathrm{lt}_{1}$ & $12 \mathrm{~mm}$ \\
$\mathrm{lt}$ & 14 & & \\
\hline
\end{tabular}

then integrated into the feeding system. Table 3 summarizes all the dimensions of the radiating element shown in Figure 4.

The photograph of the realized dual-polarized antennafilter is shown in Figure 5.

In Figure 6, a good agreement between computed and measured antenna scattering parameters can be observed.

From Figure 6 it appears that a bandwidth of $74 \%$ is achieved when maintaining the $\left|S_{11}\right|$ below $-10 \mathrm{~dB}$, which covers the required operating frequency band from $2.7 \mathrm{GHz}$ to $5.9 \mathrm{GHz}$. The electrical isolation between the input ports of the dual-polarized antenna is higher than $18 \mathrm{~dB}$ over the whole antenna operating frequency band. Furthermore, higher harmonics are effectively suppressed. The total size 


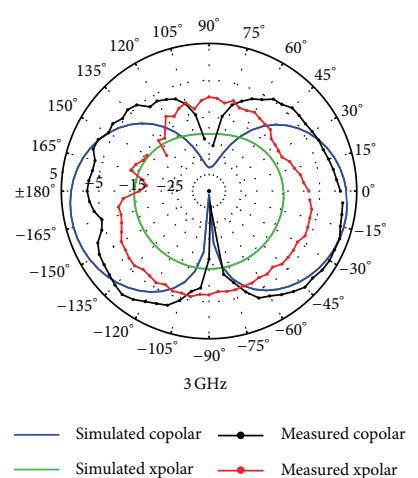

(a)

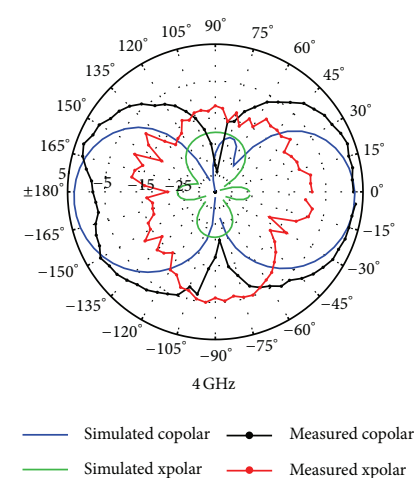

(b)

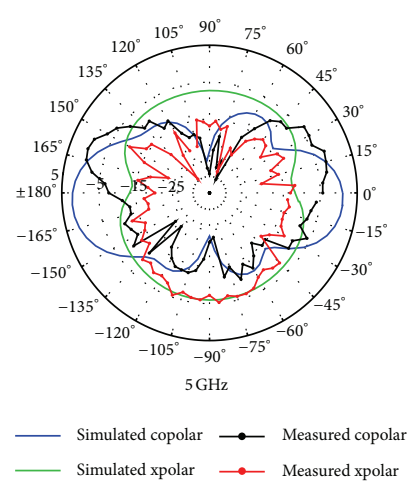

(c)

FIgURE 8: Simulated and measured radiation pattern in the E-plane (yoz) $(10 \mathrm{~dB} / \mathrm{div})$.

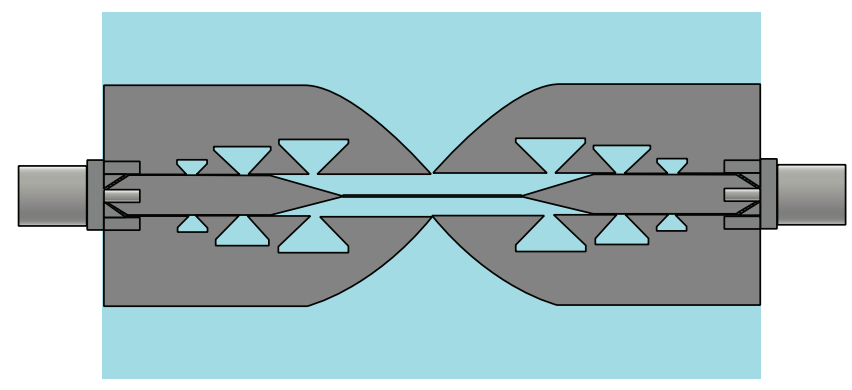

FIGURE 9: Back-to-back configuration of the filter.

of the antenna is $0.6 \times 0.6 \lambda_{0}^{2}$, where $\lambda_{0}$ is the free-space wavelength at $2.7 \mathrm{GHz}$.

Figures 7 and 8 illustrate the simulated and the measured copolar and cross-polar realized gain radiation patterns in the E- and $\mathrm{H}$-planes at 3, 4, and $5 \mathrm{GHz}$ for port 1 . The port 1 is fed while the port 2 is connected to a $50 \Omega$ load.

The radiation patterns (Figures 7 and 8 ) show that the radiation mechanism is similar to a conventional bowtie antenna. If we consider that the antenna is fed at port 1 , large surface currents are located on the edges of the vertical antenna. Due to the symmetry of each radiating element and the low level of coupling between the two ports, the $x$-components of the currents are in opposite phase and thus do not contribute significantly to the radiation. The $y$-components of the current are then responsible for the radiation and are similar to that of a half-wave dipole. This radiation mechanism occurs in the operating frequency band of the antenna, from the lowest frequency where the overall length is equal to a half wavelength to the highest frequency given by the cut-off frequency of the DGS filter. The radiation patterns in E- and $\mathrm{H}$ - planes (Figures 7 and 8) confirm this behavior. In $\mathrm{H}$-plane (Figure 7), antenna has an omnidirectional dipole-type radiation pattern from $2.7 \mathrm{GHz}$ to $5.9 \mathrm{GHz}$. In the same bandwidth, the radiation pattern in Eplane (Figure 8) is also close to the cardioid-shaped radiation pattern of a dipole. The cross-polar radiation pattern level, due to the $x$-components of the current, is $10 \mathrm{~dB}$ less than the copolar radiation pattern level, over the whole operating frequency band. The broadside realized gain varies between
$3 \mathrm{~dB}$ and $5 \mathrm{~dB}$. In H-plane, a good agreement between numerical and measurement results is achieved. In E-plane, there is a close agreement between simulated and measured patterns except at $5 \mathrm{GHz}$. This disagreement may be due to the presence of the antenna positioning mast in the anechoic chamber leading to a field perturbation.

\section{General Discussion}

The main disadvantage of a DGS filter is that it may radiate. In fact, the DGS structures can be viewed as a slot antenna [6]. In order to study the radiation characteristics of the DGS filter, the back-to-back configuration, as shown in Figure 9, has been numerically analyzed using CST Microwave Studio.

The comparison of the computed realized gain of the proposed antenna and that of the filter (see Figure 9) in the $\mathrm{H}$ - and E-plane are depicted in Figures 10 and 11, respectively.

As can be seen, both structures have the same polarization in the operating frequency band. Furthermore, Figure 12, which represents the peak realized gain versus frequency, shows that the realized gain of the filter is less than $0 \mathrm{~dB}$ until $21 \mathrm{GHz}$. Thus, it may be considered that the filter does not radiate efficiently at and below $21 \mathrm{GHz}$.

\section{Conclusion}

In this paper, a dual-polarized wideband bowtie CPW-fed antenna having wideband harmonic suppression using three 

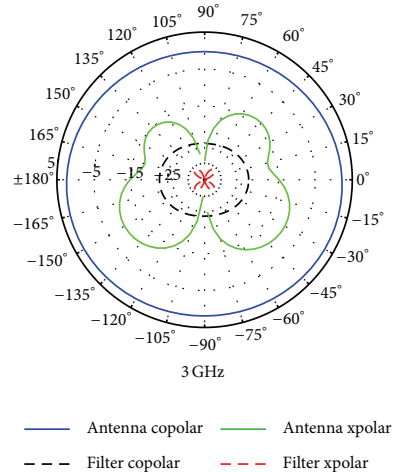

(a)

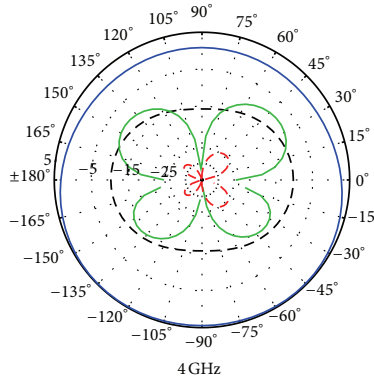

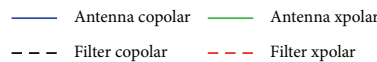

(b)

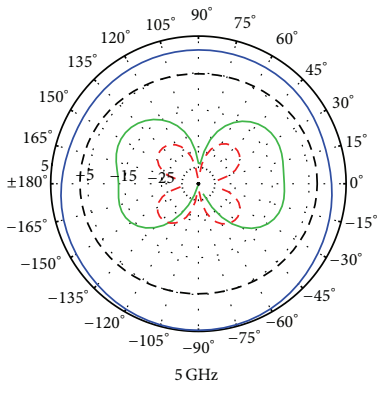

- Antenna copolar - Antenna xpola

(c)

FIGURE 10: Simulated radiation pattern of the antenna and the filter in the H-plane (10 dB/div).

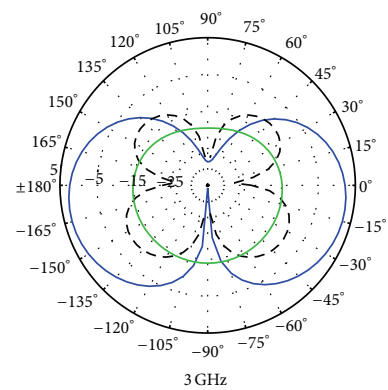

- Antenna copolar

Filter copolar

Antenna xpolar

(a)

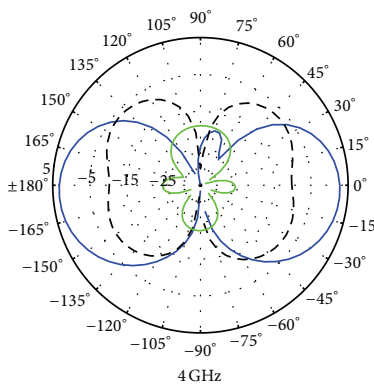

_ Antenna co-pola

- - - Filter copolar

- Antenna xpolar

(b)

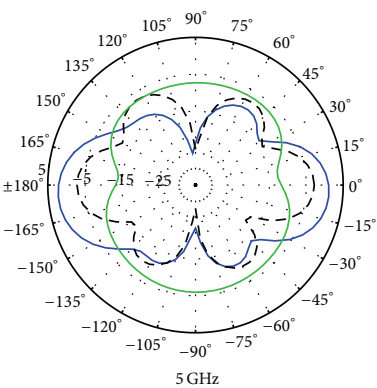

- Antenna co-polar

- - - Filter copolar

- Antenna xpolar

(c)

FIGURE 11: Simulated radiation pattern of the antenna and the filter in the E-plane (10 dB/div).

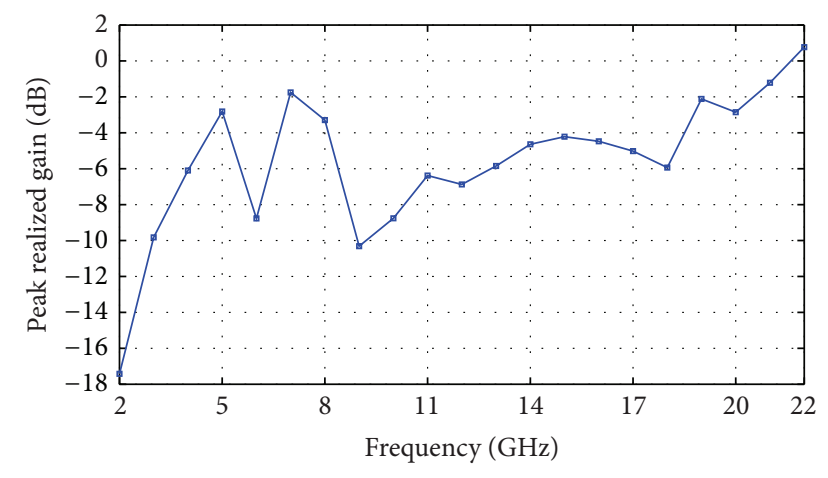

FIGURE 12: Simulated peak realized gain versus frequency of the filter in a back-to-back configuration.

nonuniform cascaded bowtie DGS unit cells has been presented. This structure provides wide bandwidth (more than an octave) and dual polarization performance. Furthermore, the antenna is interrelated to the filter and the matching circuit. The total size of the proposed structure is $0.6 \times$ $0.6 \lambda_{0}^{2}$, where $\lambda_{0}$ is the free-space wavelength at the lowest frequency. The realized dual-polarized antenna operates in the frequency range between $2.7 \mathrm{GHz}$ and $5.9 \mathrm{GHz}$ (bandwidth of about $74 \%$ ). The harmonics are effectively rejected beyond $5.9 \mathrm{GHz}$. The measured and simulated scattering parameters are in good agreement. The antenna has an omnidirectional dipole-type radiation pattern over the operating frequency band 2.7-5.9 GHz. These characteristics allow the proposed structure to cover the UWB (lower band in Europe) and IEEE 802.16 (WiMAX).

\section{Conflict of Interests}

The authors declare that there is no conflict of interests regarding the publication of this paper.

\section{References}

[1] V. Radisic, Y. Qian, and T. Itoh, "Novel architectures for highefficiency amplifiers for wireless applications," IEEE Transactions on Microwave Theory and Techniques, vol. 46, no. 11, pp. 1901-1909, 1998.

[2] S. Kwon, H. K. Yoon, and Y. J. Yoon, "Harmonic tuning antennas using slots and short-pins," in Proceedings of the IEEE Antennas and Propagation Society International Symposium, vol. 1, pp. 118-121, 2001. 
[3] Y. Horii and M. Tsutsumi, "Harmonic control by photonic bandgap on microstrip patch antenna," IEEE Microwave and Wireless Components Letters, vol. 9, no. 1, pp. 13-15, 1999.

[4] Y. J. Sung and Y.-S. Kim, "An improved design of microstrip patch antennas using photonic bandgap structure," IEEE Transactions on Antennas and Propagation, vol. 53, no. 5, pp. 17991804, 2005.

[5] V. Radisic, Y. Qian, and T. Itoh, "Broadband power amplifier integrated with slot antenna and novel harmonic tuning structure," in Proceedings of the IEEE International Microwave Symposium Digest, vol. 3, pp. 1895-1898, Baltimore, Md, USA, June 1998.

[6] H. Kim and Y. J. Yoon, "Microstrip-fed slot antennas with suppressed harmonics," IEEE Transactions on Antennas and Propagation, vol. 53, no. 9, pp. 2809-2817, 2005.

[7] L. Damaj, A. C. Lepage, and X. Begaud, "Compact wideband harmonic suppressed antenna using non-uniform cascaded defected ground structure," Microwave and Optical Technology Letters, vol. 55, no. 4, pp. 829-835, 2013.

[8] L. Damaj, X. Begaud, and A.-C. Lepage, "Wideband antenna with wideband harmonic suppression using non-uniform defected ground structure," in Proceedings of the 15th International Symposium on Antenna Technology and Applied Electromagnetics (ANTEM '12), pp. 1-4, June 2012.

[9] P. Bernardi, R. Cicchetti, and O. Testa, "An accurate UTD model for the analysis of complex indoor radio environments in microwave WLAN systems," IEEE Transactions on Antennas and Propagation, vol. 52, no. 6, pp. 1509-1520, 2004.

[10] C.-S. Kim, J.-S. Park, D. Ahn, and J.-B. Lim, "A novel 1-D periodic defected ground structure for planar circuits," IEEE Microwave and Wireless Components Letters, vol. 10, no. 4, pp. 131-133, 2000.

[11] J.-S. Lim, C.-S. Kim, Y.-T. Lee, D. Ahn, and S. Nam, "A spiralshaped defected ground structure for coplanar waveguide," IEEE Microwave and Wireless Components Letters, vol. 12, no. 9, pp. 330-332, 2002.

[12] H.-H. Xie, Y.-C. Jiao, J.-X. Huang, and L. Zhang, "Ultra-wide stopband low-pass filter with bowtie defected ground structure," in Proceedings of the International Conference on Microwave and Millimeter Wave Technology (ICMMT '10), pp. 1655-1657, Chengdu, China, May 2010. 

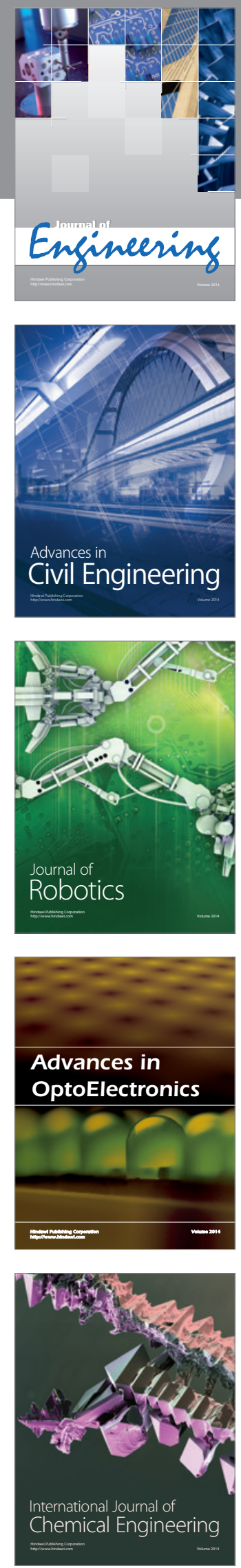

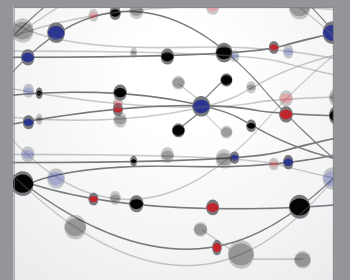

The Scientific World Journal
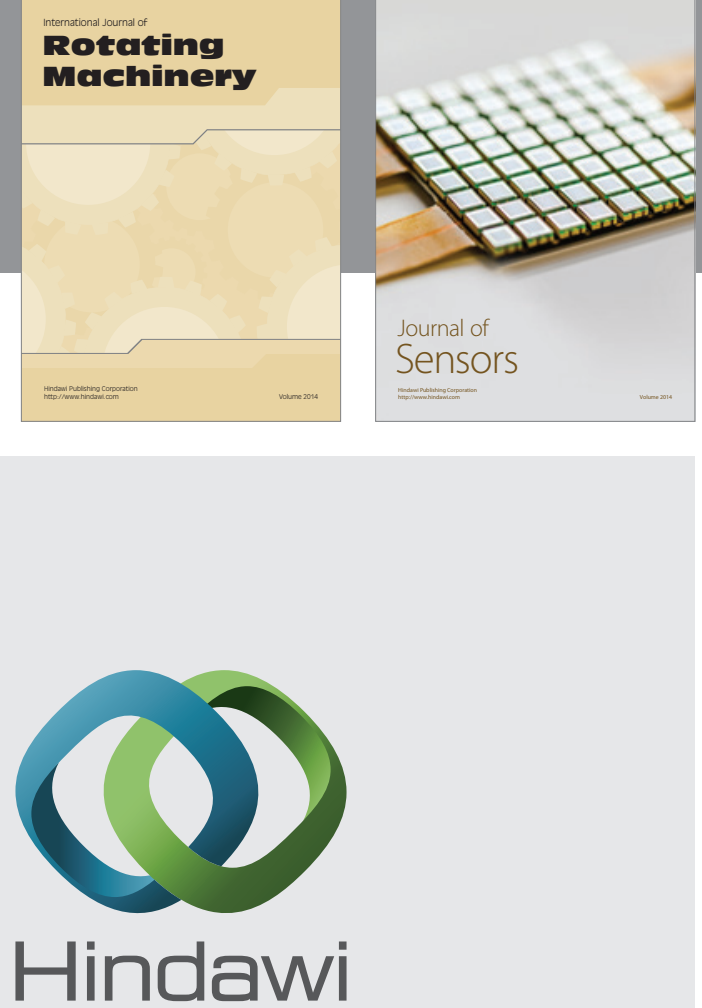

Submit your manuscripts at http://www.hindawi.com
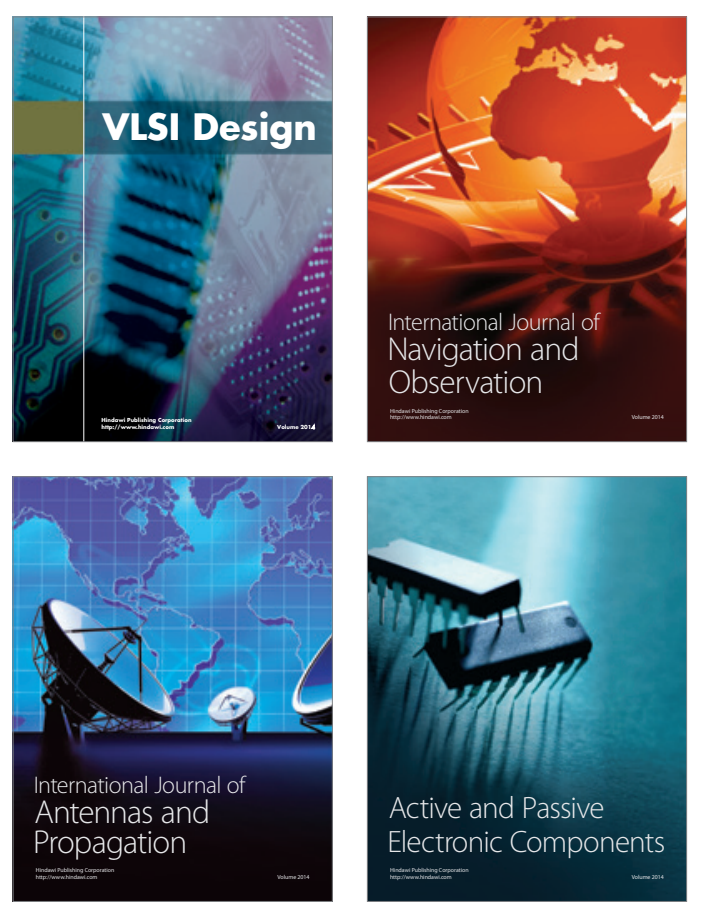
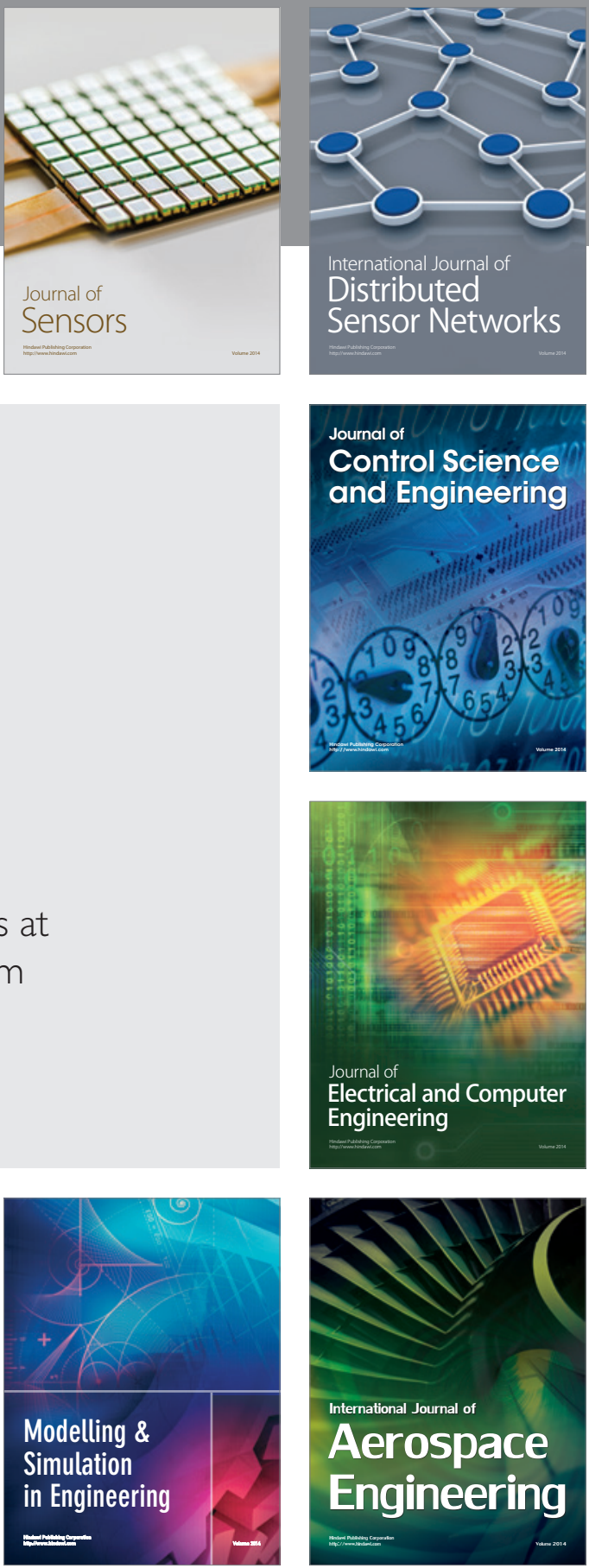

Journal of

Control Science

and Engineering
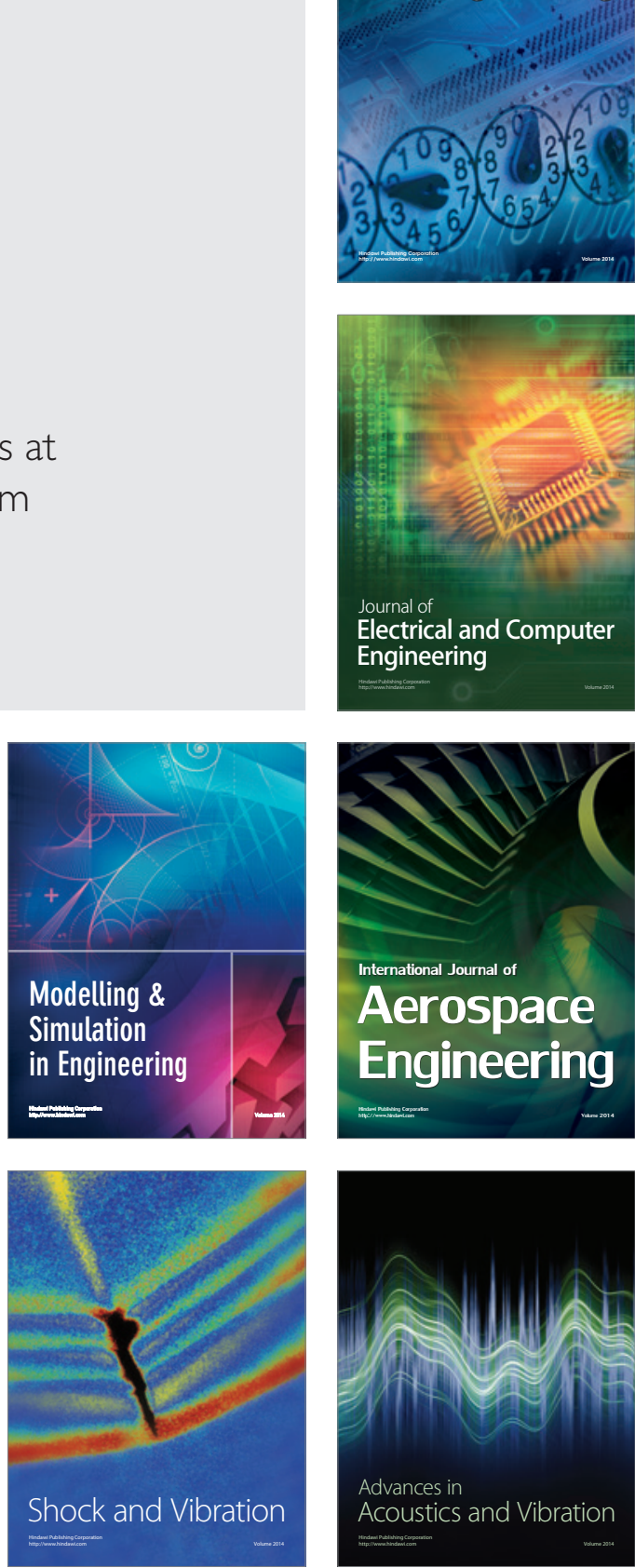